\title{
Fibroblast activation protein-positive fibroblasts promote tumor progression through secretion of CCL2 and interleukin- 6 in esophageal squamous cell carcinoma
}

\author{
Nobuhide Higashino $^{1,2} \cdot$ Yu-ichiro Koma ${ }^{1}$ Masayoshi Hosono ${ }^{1,2} \cdot$ Nobuhisa Takase $^{1,2} \cdot$ Maiko Okamoto $^{1} \cdot$

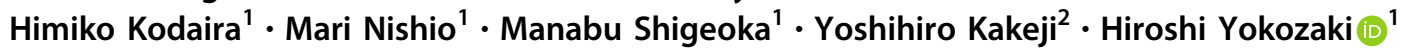

Received: 8 June 2018 / Revised: 18 November 2018 / Accepted: 27 November 2018 / Published online: 25 January 2019

(c) United States \& Canadian Academy of Pathology 2019

\begin{abstract}
Esophageal squamous cell carcinoma (ESCC) is a highly aggressive tumor with frequent recurrence even after curative resection. The tumor microenvironment, which consists of non-cancer cells, such as cancer-associated fibroblasts (CAFs) and tumor-associated macrophages (TAMs), was recently reported to promote several cancers, including ESCC. However, the role of CAF as a coordinator for tumor progression in ESCC remains to be elucidated. In our immunohistochemical investigation of ESCC tissues, we observed that the intensity of expression of two CAF markers-alpha smooth muscle actin $(\alpha$ SMA) and fibroblast activation protein (FAP)—in the tumor stroma was significantly correlated with the depth of tumor invasion, lymph node metastasis, advanced pathological stage, and poor prognosis. We co-cultured human bone marrowderived mesenchymal stem cells (MSCs) with ESCC cells and confirmed the induction of FAP expression in the co-cultured MSCs. These FAP-positive MSCs (which we defined as CAF-like cells) promoted the cell growth and migration of ESCC cells and peripheral blood mononuclear cell-derived macrophage-like cells. CAF-like cells induced the M2 polarization of macrophage-like cells. A cytokine array and ELISA revealed that CAF-like cells secreted significantly more CCL2, Interleukin-6, and CXCL8 than MSCs. These cytokines promoted the migration of tumor cells and macrophage-like cells. The silencing of FAP in CAF-like cells attenuated cytokine secretion. We compared cell signaling of MSCs, CAF-like cells, and FAP-silenced CAF-like cells; PTEN/Akt and MEK/Erk signaling were upregulated and their downstream targets, NF$\kappa \mathrm{B}$ and $\beta$-catenin, were also activated with FAP expression. Silencing of FAP attenuated these effects. Cytokine secretion from CAF-like cells were attenuated by inhibitors against these signaling pathways. These findings indicate that the collaboration of CAFs with tumor cells and macrophages plays a pivotal role in tumor progression, and that FAP expression is responsible for the tumor promotive and immunosuppressive phenotypes of CAFs.
\end{abstract}

\section{Introduction}

Esophageal cancer is the sixth leading cause of cancerrelated mortality and the eighth-most common cancer

Supplementary information The online version of this article (https:// doi.org/10.1038/s41374-018-0185-6) contains supplementary material, which is available to authorized users.

Hiroshi Yokozaki

hyoko@med.kobe-u.ac.jp

1 Division of Pathology, Department of Pathology, Kobe University Graduate School of Medicine, Kobe, Japan

2 Division of Gastro-intestinal Surgery, Department of Surgery, Kobe University Graduate School of Medicine, Kobe, Japan worldwide [1]. While esophageal adenocarcinoma is predominant in North America and Europe, esophageal squamous cell carcinoma (ESCC) dominates in Africa, South America, and Asia, including Japan [2, 3]. The prognosis of esophageal cancer is poor, with $18 \%$ overall 5 -year survival [4]. Even after extended radical esophagectomy, advanced clinical stage ESCC patients showed a high recurrence rate of $43.3 \%$ [5]. Thus, a better understanding of the molecular pathogenesis of ESCC is necessary to establish novel therapies and biomarkers.

Recent evidence indicates that the molecular mechanisms not only in tumor cells themselves but also in their surrounding environment hold the key to tumor development in many types of cancer, including ESCC [6, 7]. The tumor microenvironment consists of non-cancer cells and stroma, such as fibroblasts, macrophages, neutrophils, natural killer 
cells, dendritic cells, vascular endothelial cells, and extracellular matrix. Among them, cancer-associated fibroblasts (CAFs) are major components of cancer stroma that have an activated phenotype promoting tumor progression [8]. CAFs are reported to originate from resident tissue fibroblasts, bone marrow-derived mesenchymal stem cells (MSCs), hematopoietic stem cells, epithelial cells, and endothelial cells [9]. Although a specific CAF marker has not been established, some markers, such as alpha smooth muscle actin $(\alpha \mathrm{SMA})$ and fibroblast activation protein (FAP), are used to identify CAFs. Tumor-associated macrophages (TAMs) are also main cellular components of the tumor microenvironment. Responding to tumor-derived molecules, macrophages polarize into alternatively activated (M2) macrophages and promote tumor progression [10].

CAFs and TAMs were recently reported to collaborate to promote tumor progression. The cell-cell interactions of CAFs and TAMs activate not only tumor cells but also nontumor stromal cells by secretion of numerous factors and degradation of the extracellular matrix [11]. Our previous study showed that large numbers of infiltrating CAFs and TAMs in neuroblastoma tissue were both closely correlated with aggressive phenotypes, and we observed that the collaboration of CAFs and TAMs promotes neuroblastoma development synergistically [12]. However, the details of interactions between CAFs and TAMs in the ESCC microenvironment have not yet been elucidated.

Therefore, we sought to determine how CAFs interact with other cells to promote tumor in microenvironment. In this study, we used immunohistochemistry to examine the prognostic significance of CAFs and their correlation with the number of infiltrating TAMs in human ESCC tissues. We also investigated interactions between tumor cells, CAFs, and macrophages in vitro using ESCC cell lines, activated CAFlike MSCs, and peripheral blood mononuclear cell (PBMC)derived macrophage-like cells. Lastly, we analyzed the biological effects of FAP expressed in CAFs on co-cultured tumor cells and macrophages.

\section{Materials and methods}

\section{Reagents}

The neutralizing antibodies were as follows: Armenian hamster antibody against CCL2 (\#16-7096-81; eBioscience, San Diego, CA), rabbit antibody against Interleukin-6 (IL-6; \#ab6672; Abcam, Cambridge, UK), and mouse antibody against CXCL8 (\#ab18672; Abcam). The inhibitors against PI3K (LY294002) and MEK1/2 (PD98059) were purchased from Cell Signaling Technology (Beverly, MA). The inhibitors against NF- $\mathrm{kB}$ (Bay11-7082) and $\beta$-catenin (MSAB) were obtained from Sigma-Aldrich (St. Louis, MO).
Tissue samples and immunohistochemical analyses

A total of 70 sporadic human ESCCs surgically removed at Kobe University Hospital (Kobe, Japan) from 2005 to 2010 were used. None of the patients had received adjuvant chemotherapy or radiotherapy before surgery. Informed consent for the use of tissue samples was obtained from all patients, and the study was approved by the Kobe University Institutional Review Board. All resected specimens were fixed with $10 \%$ formalin and embedded in paraffin wax. Each sample was categorized according to the Japanese Classification of Esophageal Cancer proposed by the Japan Esophageal Society and the TNM classification of the Union for International Cancer Control [13, 14].

Immunohistochemistry was performed using EnVision Dual Link System-HRP with 3.3'-diaminobenzidine (Dako Cytomation, Glostrup, Denmark). The following antibodies were used to detect cellular antigens: mouse antibody against $\alpha$ SMA (1:500, A5228; Sigma-Aldrich) and sheep antibody against FAP (1:200, AF3715; R\&D Systems, Minneapolis, $\mathrm{MN})$. We evaluated the proportion of immunohistochemistrypositive area of the stroma around the invasive front per 40x field as low ( $\leq 30 \%)$ and high $(>30 \%)$.

\section{Cell lines and cell cultures}

Three ESCC cell lines (TE-8, TE-9, and TE-15) were obtained from the RIKEN BioResource Center (Tsukuba, Japan) [15] and maintained in RPMI-1640 (Wako, Osaka, Japan) with 10\% FBS (Sigma-Aldrich) and 1\% antibioticantimycotic (Invitrogen, Carlsbad, CA). We purchased human MSCs from the American Type Culture Collection (ATCC, Manassas, VA) and maintained them in DMEM low-glucose (Wako) with 10\% FBS and 1\% antibiotic-antimycotic. All cells were confirmed to be mycoplasma-negative by a Venor Gem Classic Mycoplasma Detection kit (Minerva Biolabs, Berlin, Germany). The individuality of the TE series ESCC cell lines was confirmed by a short tandem repeat (STR) analysis at RIKEN and at the Cell Resource Center for Biomedical Research, Institute of Development, Aging and Cancer, Tohoku University in 2009 and 2010 (Sendai, Japan). Human MSCs were confirmed to be negative for CD14, CD31, CD34, CD45, and CD19, but positive for CD29, CD44, CD90, CD105, CD166, and CD73.

\section{Preparation of macrophage-like cells and CAF-like MSCs}

PBMCs were obtained from healthy volunteer donors after informed consent was obtained. CD14-positive peripheral blood monocytes (PBMos) were purified from PBMCs using the Auto MACS ${ }^{\circledR}$ Pro Separator (Miltentyi Biotec, Bergisch Gladbach, Germany). PBMos were 
cultured with M-CSF ( $25 \mathrm{ng} / \mathrm{ml}$; R\&D Systems) for 6 days to induce macrophage-like cells. In order to induce the CAF-like MSCs, $5 \times 10^{4}$ human MSCs were seeded in the bottom chamber of a 6-well plate and co-cultured with $1.5 \times 10^{5}$ TE cells for 7 days using the cell culture inserts with a $0.4-\mu \mathrm{m}$ pore-size filter (BD Falcon, Lincoln Park, $\mathrm{NY}$ ). The medium was changed 3 days after seeding. As a mono-cultured control, MSCs were seeded in the same manner. We defined CAF-like cells co-cultured with TE8, TE-9, and TE-15 cells as CAF8, CAF9, and CAF15 cells, respectively.

\section{Quantitative reverse transcription-PCR (qRT-PCR)}

Total RNA was extracted from cultured cells using an RNeasy Mini Kit (Qiagen, Hilden, Germany). Quantitative RT-PCR was performed using the following probes: ACTA2 (Hs00426835_g1), FAP (Hs00990806_m1), CD163 (Hs00174705_m1), MSRI (Hs00234007_m1), IL10 (Hs00961622_m1), CD274 (Hs00204257_m1), and ACTB ( $\beta$ actin) (Hs01060665_g1) (Applied Biosystems, Foster City, CA) on an ABI StepOne Real-time PCR system (Applied Biosystems) using TaqMan Gene Expression Master Mix (Applied Biosystems). Target gene expression was normalized to $A C T B$ levels in the respective samples as an internal control.

\section{Western blotting}

Cells were lysed on ice with a RIPA Lysis and Extraction Buffer (Thermo Fisher Scientific, Waltham, MA) containing $1 \%$ protease inhibitor and $1 \%$ phosphatase inhibitor cocktail (Sigma-Aldrich). The resulting lysates were separated on 5-20\% SDS polyacrylamide gels and transferred to a membrane with an iBlot Gel Transfer Stack (Invitrogen). The membrane was blocked with 5\% skim milk and then incubated with primary and secondary antibodies. The protein bands were detected with ImmunoStar Reagents (Wako). Details of the primary and secondary horseradish peroxidase (HRP)conjugated antibodies are listed in Supplementary Table S1.

\section{Immunofluorescence}

Cells were seeded onto coverslips overnight, fixed with $4 \%$ paraformaldehyde phosphate buffer solution (Wako) and incubated with mouse antibody against $\alpha$ SMA (1:1000, A5228; Sigma-Aldrich) and sheep antibody against FAP (1:500; AF3715, R\&D Systems) at $4^{\circ} \mathrm{C}$ overnight. The cells were then incubated with Alexa Fluor 488-conjugated donkey anti-sheep secondary antibody (Jackson ImmunoResearch Laboratories, West Grove, PA) and Cy3-conjugated donkey anti-mouse IgG secondary antibody (Jackson) at room temperature for $1 \mathrm{~h}$. The nuclei were stained with DAPI (Wako). Images were taken with a Zeiss LSM 700 laser-scanning microscope and analyzed using the LSM software ZEN 2009 (Carl Zeiss, Oberkochen, Germany).

\section{Proliferation assays}

First, $2 \times 10^{4}$ TE-9 cells or $1 \times 10^{5}$ macrophage-like cells were cultured in the bottom chamber of a 24 -well plate. Then, $5 \times 10^{4}$ CAF9 cells were seeded in the upper 0.4- $\mu \mathrm{m}$ pore-size insert (BD Falcon). There were no cells in the upper insert of the control. After co-culture under the serum-free condition or treatment for $48 \mathrm{~h}$ as indicated in the Results section below, the analyses of the cell proliferation were conducted with an MTS colorimetric assay (Promega, Madison, WI). Absorbance was read at $492 \mathrm{~nm}$.

\section{In vitro migration assay}

The in vitro migration assay was performed using an $8.0-\mu \mathrm{m}$ pore-size insert (BD Falcon). First, $5 \times 10^{4} \mathrm{MSCs}$ and CAF9 cells were seeded into the lower chambers $48 \mathrm{~h}$ before the inserts were exposed. There were no cells in the lower chamber of the control. At the same time, $1 \times 10^{5}$ TE- 9 cells and macrophage-like cells were seeded in the upper inserts. When the inserts were exposed to the lower chambers, the conditioned media (CM) within the inserts and bottom chambers were changed to serum-free DMEM. After the upper inserts were exposed to the lower chambers, the cells were incubated for $48 \mathrm{~h}$ at $37^{\circ} \mathrm{C}$ in a $\mathrm{CO}_{2}$ incubator. The cells remaining in the upper surface of the membrane were removed with a cotton swab. The cells that had migrated onto the lower surface of the membrane were counted using a Diff-Quik staining kit (Sysmex, Kobe, Japan).

\section{FAP knockdown by small interfering RNA}

CAF9 cells were transfected with $20 \mathrm{nM}$ small interfering RNA (siRNA) targeting human FAP (FAP $\alpha$ siRNA, sc62292; Santa Cruz) using Lipofectamine RNAiMAX (Invitrogen). Control siRNA (Sigma-Aldrich) was used as the negative control. For measurement of cytokine secretion from CAF9 cells, an siRNA with a second independent sequence was also used (MISSION siRNA human FAP, SASI_Hs02_00337654; Sigma-Aldrich).

\section{Cytokine array}

After the induction of CAF9 cells or control MSCs by coculture with or without TE-9 cells as described above, the CM was changed to serum-free DMEM. After $48 \mathrm{~h}$, we 
analyzed the CM with a Proteome Profiler Human Cytokine Array Kit (R\&D Systems) according to the manufacturer's instructions.

\section{Enzyme-linked immunosorbent assay (ELISA)}

The CM of CAF9 cells or control MSCs was analyzed with Quantikine ELISA Human MCP-1, IL-6, and IL-8 immunoassays (R\&D Systems) according to the manufacturer's instructions. The optical density of each well was read at 450 and $570 \mathrm{~nm}$. The concentration of each cytokine was calculated using a standard curve and the measured absorbance and normalized to total protein content of cell lysate.

\section{Statistical analysis}

All experiments were performed in triplicate and independently conducted three times. The results are expressed as the mean \pm SEM, and statistical significance was analyzed by two-sided Student's $t$-test and by the Tukey-Kramer test when there were more than two groups. The relationships between clinicopathological factors and immunohistochemistry were estimated by $\chi^{2}$-test. Disease-free and overall survival curves were estimated by the Kaplan-Meier method and compared by log-rank test. The significance of parameters in the univariate and multivariate analyses was tested using the Cox proportional hazard regression model. A $p$-value $<0.05$ was considered significant. Statistical analyses were carried out using SPSS Statistics ver. 22 (IBM, Chicago, IL).

\section{Results}

\section{The expression levels of aSMA and FAP were significantly correlated with clinicopathological factors and the prognosis of ESCC patients}

Using immunohistochemistry, we first divided the 70 ESCC samples into high and low groups on the basis of the staining area of $\alpha \mathrm{SMA}$ or FAP around the invasive front (Fig. 1a, b). We found that a high expression of $\alpha$ SMA or FAP was significantly correlated with the depth of tumor invasion, lymphatic vessel invasion, blood vessel invasion, lymph node metastasis, pathological stage, a high number of infiltrating CD68-positive macrophages, CD163-positive macrophages, and CD204-positive macrophages (Table 1). In the immunofluorescence analysis, FAP-positive stromal cells coexisted with CD163- or CD204- positive macrophages (Supplementary Fig. S1A, B).

We next analyzed the prognostic value of $\alpha$ SMA and that of FAP using the follow-up data of 69 of the 70
ESCC patients (excluding the single patient who could not be followed). Kaplan-Meier analysis showed that the patients with a high expression of $\alpha$ SMA or FAP had significantly shorter disease-free survival (DFS). The patients with a high FAP expression also had significantly shorter overall survival (OS) (Fig. 1c). Univariate Cox regression analysis of prognostic factors for DFS showed that a high expression of $\alpha$ SMA or FAP and a high number of infiltrating CD68-positive or CD204positive macrophages correlated significantly with poor DFS (Table 2).

\section{Co-culture with ESCC cell lines induced FAP expression in MSCs}

We previously reported the tumor-promoting effects of $\alpha$ SMA-induced MSCs that were cultured with conditioned medium of neuroblastoma cell lines [12]. In the present study, to investigate whether the co-culture with ESCC cells could induce the CAF markers in MSCs, we performed an indirect co-culture of MSCs with TE-8, TE-9 and TE-15 ESCC cells and analyzed the $\alpha$ SMA and FAP expression at the mRNA and protein levels (Fig. 2a).

As MSCs express $\alpha$ SMA themselves, the effect of coculture with ESCC cells on the $\alpha$ SMA induction was less. Significant FAP expression was induced in the MSCs cocultured with each of the three ESCC cell lines, at the mRNA and protein levels (Fig. 2b, c). We defined MSCs cocultured with TE-9 cells as CAF9 cells and used them in the subsequent experiment, since the $\alpha \mathrm{SMA}$ and FAP inductions were stronger in the TE- 9 cells than in the TE- 8 or TE-15 cells. Upregulation of CAF markers in CAF9 cells was also confirmed by immunofluorescence (Fig. 2d).

\section{CAF9 cells promoted the proliferation and migration of TE-9 cells and macrophage-like cells and induced the M2 polarization of macrophage-like cells}

To confirm the interactions between tumor cells and stroma cells, we next investigated the effects of CAF9 cells on TE9 cells and on macrophage-like cells induced from PBMos using an indirect co-culture system. MSCs and CAF8 cells were also used for comparison because their FAP expression was weaker than CAF9 cells. Both CAF8 and CAF9 cells promoted significant proliferation of TE9 cells. CAF8 and CAF9 cells also promoted proliferation of macrophagelike cells, but effect was greater in CAF9 cells than in CAF8 cells (Fig. 3a). MSCs and CAF8 cells promoted migration of TE-9 cells. However, CAF9 cells caused a nearly two-fold greater effect than MSCs or CAF8 cells. While MSCs did not promote migration of macrophage-like cells, CAF9 cells did so, and to a lesser extent, CAF8 cells (Fig. 3b). 


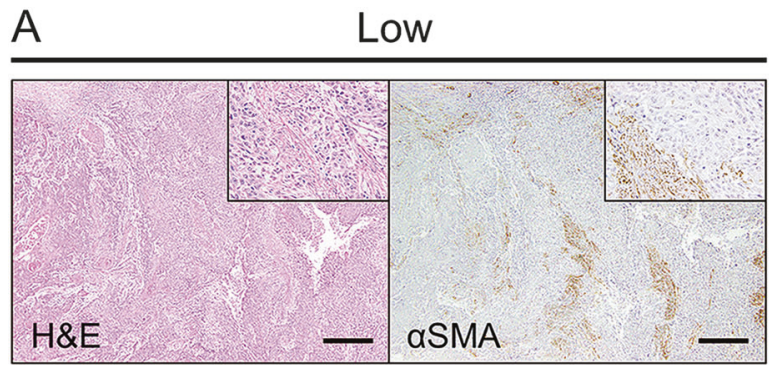

B

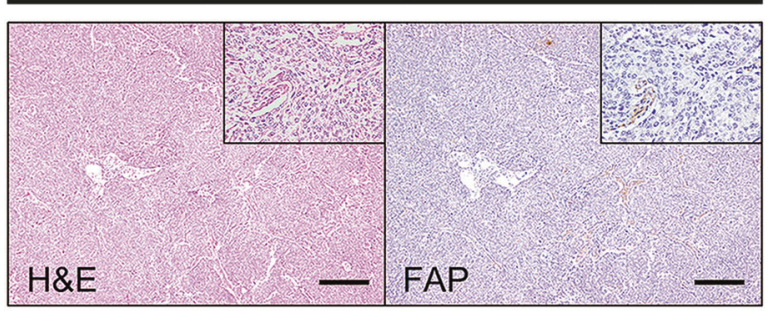

C

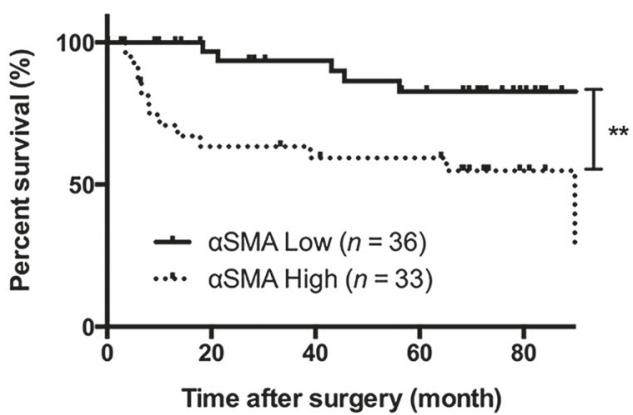

Overall survival

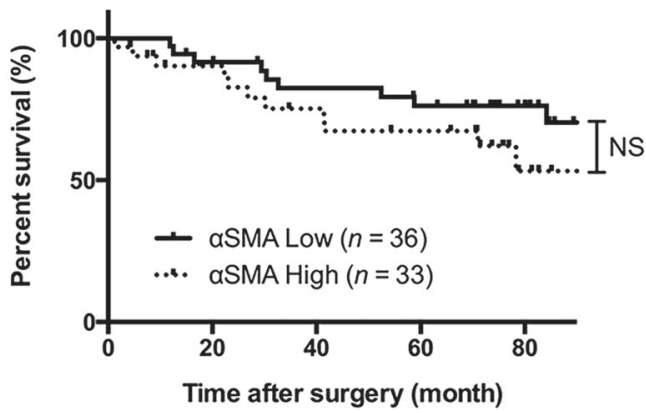

Fig. 1 High expression of $\alpha$ SMA or FAP in human ESCC tissues was associated with poor prognosis. Immunoreactivity around the invasive front of ESCC was assessed and divided into high and low groups based on the staining area (high: $>30 \%$; low: $\leq 30 \%$ ). a Low (left) and high (right) $\alpha$ SMA cases. b Low (left) and high (right) FAP cases.

Interestingly, M2 macrophage markers, such as $C D 163$, MSRI (CD204) and IL10, and CD274 (PD-L1) were upregulated in the macrophage-like cells co-cultured with CAF9 cells, but not in the macrophage-like cells co-cultured with MSCs or CAF8 cells (Fig. 3c). These results indicate that FAP induced the tumor- and macrophage-promoting phenotype of CAFs.
High

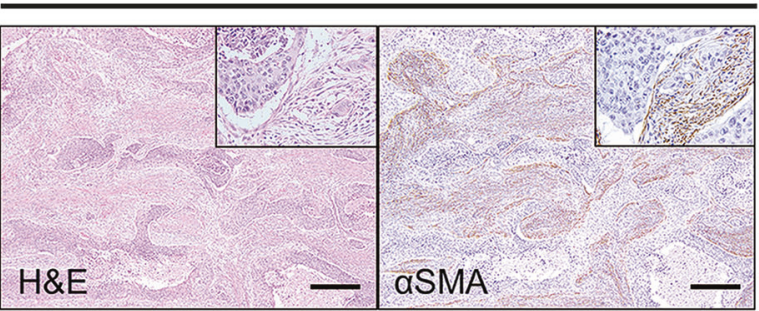

High
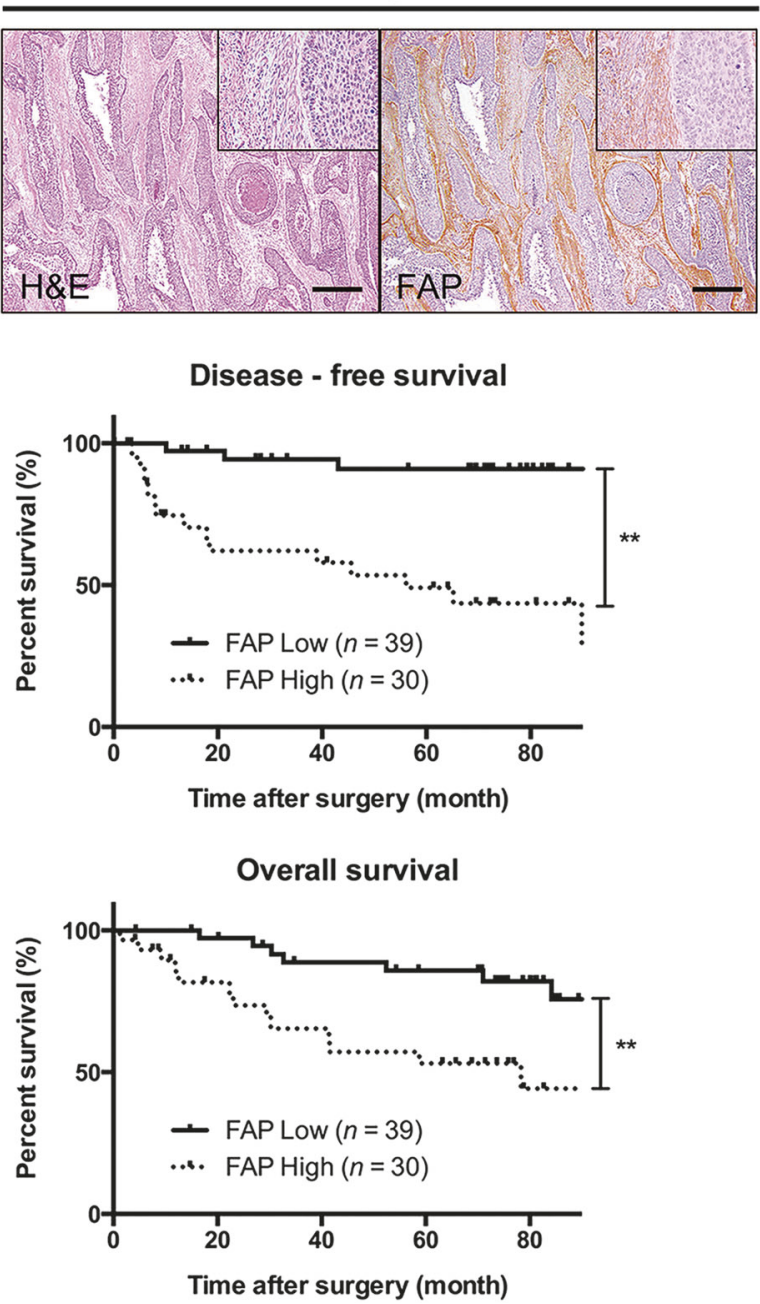

Original magnification: 40x. Inset magnification: 400x. Scale bar, $500 \mu \mathrm{m}$. c Kaplan-Meier analyses of the disease-free survival and overall survival of ESCC patients divided into high and low groups based on their expression levels of $\alpha$ SMA or FAP. ** $p<0.01$ by $\log$ rank test. NS not significant

\section{Cytokine secretion from MSCs were upregulated by co-culture with TE-9 cells}

Next, we analyzed cytokine secretion from CAF9 cells to investigate the mechanism by which CAF-like cells promoted the migration and proliferation of tumor cells and macrophage-like cells. The cytokine array showed higher 
Table 1 Expression level of $\alpha$ SMA and FAP in ESCC and their correlation with clinicopathological data and infiltrating macrophages phenotypes

\begin{tabular}{|c|c|c|c|c|c|c|c|}
\hline & \multirow[b]{2}{*}{ Number } & \multicolumn{2}{|c|}{ Expression of $\alpha \mathrm{SMA}^{\mathrm{a}}$} & \multirow[b]{2}{*}{$p$-value ${ }^{*}$} & \multicolumn{2}{|c|}{ Expression of $\mathrm{FAP}^{\mathrm{a}}$} & \multirow[b]{2}{*}{$p$-value } \\
\hline & & $\begin{array}{l}\text { Low } \\
(n=36)\end{array}$ & $\begin{array}{l}\text { High } \\
(n=34)\end{array}$ & & $\begin{array}{l}\text { Low } \\
(n=39)\end{array}$ & $\begin{array}{l}\text { High } \\
(n=31)\end{array}$ & \\
\hline \multicolumn{8}{|l|}{ Age } \\
\hline$<65$ & 33 & 17 & 16 & 1.000 & 17 & 16 & 0.631 \\
\hline$\geq 65$ & 37 & 19 & 18 & & 22 & 15 & \\
\hline \multicolumn{8}{|c|}{ Histological grade $e^{b}$} \\
\hline $\begin{array}{l}\text { HGIEN + } \\
\text { WDSCC }\end{array}$ & 16 & 10 & 6 & 0.398 & 8 & 8 & 0.775 \\
\hline $\begin{array}{l}\text { MDSCC }+ \\
\text { PDSCC }\end{array}$ & 54 & 26 & 28 & & 31 & 23 & \\
\hline \multicolumn{8}{|c|}{ Depth of tumor invasion ${ }^{b}$} \\
\hline $\mathrm{T} 1$ & 49 & 33 & 16 & $<0.001$ & 35 & 14 & $<0.001$ \\
\hline $\mathrm{T} 2+\mathrm{T} 3$ & 21 & 3 & 18 & & 4 & 17 & \\
\hline \multicolumn{8}{|c|}{ Lymphatic vessel invasion $^{b}$} \\
\hline Negative & 37 & 26 & 11 & 0.002 & 29 & 8 & $<0.001$ \\
\hline Positive & 33 & 10 & 23 & & 10 & 23 & \\
\hline \multicolumn{8}{|c|}{ Blood vessel invasion ${ }^{b}$} \\
\hline Negative & 43 & 28 & 15 & 0.006 & 29 & 14 & 0.015 \\
\hline Positive & 27 & 8 & 19 & & 10 & 17 & \\
\hline \multicolumn{8}{|c|}{ Lymph node metastasis ${ }^{b}$} \\
\hline Negative & 43 & 30 & 13 & $<0.001$ & 31 & 12 & 0.001 \\
\hline Positive & 27 & 6 & 21 & & 8 & 19 & \\
\hline \multicolumn{8}{|l|}{ Stage $e^{c}$} \\
\hline $0+\mathrm{I}$ & 38 & 28 & 10 & $<0.001$ & 27 & 11 & 0.008 \\
\hline $\mathrm{II}+\mathrm{III}+\mathrm{IV}$ & 32 & 8 & 24 & & 12 & 20 & \\
\hline \multicolumn{8}{|c|}{ CD68-positive cells ${ }^{d}$} \\
\hline Low & 35 & 24 & 11 & 0.008 & 26 & 9 & 0.004 \\
\hline High & 35 & 12 & 23 & & 13 & 22 & \\
\hline \multicolumn{8}{|c|}{ CD163-positive cells ${ }^{d}$} \\
\hline Low & 35 & 25 & 10 & 0.002 & 26 & 9 & 0.004 \\
\hline High & 35 & 11 & 24 & & 13 & 22 & \\
\hline \multicolumn{8}{|c|}{ CD204-positive cells ${ }^{d}$} \\
\hline Low & 34 & 31 & 3 & $<0.001$ & 29 & 5 & $<0.001$ \\
\hline High & 36 & 5 & 31 & & 10 & 26 & \\
\hline
\end{tabular}

HGIEN high-grade intraepithelial neoplasia, WDSCC well-differentiated squamous cell carcinoma, $M D S C C$ moderately differentiated squamous cell carcinoma, $P D S C C$ poorly differentiated squamous cell carcinoma, $T 1 a$ tumor invades mucosa, $T 1 b$ tumor invades submucosa, $T 2$, tumor invades muscularis propria, $T 3$ tumor invades adventitia

*Data were analyzed by $\chi^{2}$-test. $p<0.05$ was considered statistically significant

${ }^{a}$ Expression of $\alpha$ SMA and FAP in ESCC tissue was divided into high and low groups

${ }^{\mathrm{b}}$ According to the Japanese Classification of Esophageal Cancer [13]

${ }^{\mathrm{c}}$ According to the TNM classification by UICC [14]

${ }^{\mathrm{d}}$ The median values of CD68-positive, CD163-positive or CD204-positive macrophage numbers in cancer nests and stroma within the areas were used to divide the patients into low and high groups levels of CCL2, Interleukin-6 (IL-6), and CXCL8 secretion in CAF9 cells compared to MSCs, and the significant increases of these cytokines were confirmed by ELISA (Fig. 4a, b).
We then added the neutralizing antibody against these cytokines to the CAF9 co-culture conditions with TE-9 or macrophage-like cells. Although the antibodies against these cytokines did not show a suppressive effect on the cell 
Table 2 Univariate and multivariate Cox regression analysis of prognostic factors for disease-free survival

\begin{tabular}{|c|c|c|c|c|c|c|c|}
\hline & \multirow[b]{2}{*}{ Number } & \multicolumn{3}{|c|}{ Univariate analysis } & \multicolumn{3}{|c|}{ Multivariate analysis } \\
\hline & & HR & $95 \% \mathrm{CI}$ & $p$-value* & HR & $95 \% \mathrm{CI}$ & $p$-value* \\
\hline \multicolumn{8}{|l|}{ Age } \\
\hline$<65$ & 33 & 0.645 & $0.249-1.671$ & 0.367 & & & \\
\hline$\geq 65$ & 36 & & & & & & \\
\hline \multicolumn{8}{|c|}{ Histological grade ${ }^{a}$} \\
\hline $\begin{array}{l}\text { HGIEN + } \\
\text { WDSCC }\end{array}$ & 16 & 2.0 & $0.574-6.972$ & 0.277 & & & \\
\hline $\begin{array}{l}\text { MDSCC + } \\
\text { PDSCC }\end{array}$ & 53 & & & & & & \\
\hline \multicolumn{8}{|c|}{ Depth of tumor invasion ${ }^{a}$} \\
\hline $\mathrm{T} 1$ & 49 & 8.856 & $3.137-25.001$ & $<0.001$ & 3.179 & $0.888-11.374$ & 0.075 \\
\hline $\mathrm{T} 2+\mathrm{T} 3$ & 20 & & & & & & \\
\hline \multicolumn{8}{|c|}{ Lymphatic vessel invasion $^{a}$} \\
\hline Negative & 37 & 3.975 & $1.414-11.174$ & 0.009 & & & \\
\hline Positive & 32 & & & & & & \\
\hline \multicolumn{8}{|c|}{ Blood vessel invasion ${ }^{a}$} \\
\hline Negative & 43 & 2.232 & $0.879-5.667$ & 0.091 & & & \\
\hline Positive & 26 & & & & & & \\
\hline \multicolumn{8}{|c|}{ Lymph node metastasis ${ }^{a}$} \\
\hline Negative & 43 & 7.082 & $2.322-21.599$ & 0.001 & 2.709 & $0.624-11.757$ & 0.183 \\
\hline Positive & 26 & & & & & & \\
\hline \multicolumn{8}{|l|}{ Stage $^{b}$} \\
\hline $0+\mathrm{I}$ & 38 & 8.217 & $2.371-28.473$ & 0.001 & & & \\
\hline $\mathrm{II}+\mathrm{III}+\mathrm{IV}$ & 31 & & & & & & \\
\hline \multicolumn{8}{|l|}{$\alpha \mathrm{SMA}^{\mathrm{c}}$} \\
\hline Low & 36 & 3.702 & $1.317-10.401$ & 0.013 & & & \\
\hline High & 33 & & & & & & \\
\hline \multicolumn{8}{|l|}{ FAP $^{c}$} \\
\hline Low & 39 & 9.51 & $2.743-32.973$ & $<0.001$ & 4.388 & $1.013-19.017$ & 0.048 \\
\hline High & 30 & & & & & & \\
\hline \multicolumn{8}{|c|}{ CD68-positive cells $^{d}$} \\
\hline Low & 35 & 2.933 & $1.037-8.293$ & 0.043 & & & \\
\hline High & 34 & & & & & & \\
\hline \multicolumn{8}{|c|}{ CD163-positive cells ${ }^{d}$} \\
\hline Low & 35 & 2.156 & $0.807-5.763$ & 0.126 & & & \\
\hline High & 34 & & & & & & \\
\hline \multicolumn{8}{|c|}{ CD204-positive cells ${ }^{d}$} \\
\hline Low & 34 & 4.297 & $1.413-13.07$ & 0.010 & 0.723 & $0.182-2.874$ & 0.646 \\
\hline High & 35 & & & & & & \\
\hline
\end{tabular}

HGIEN high-grade intraepithelial neoplasia, WDSCC well-differentiated squamous cell carcinoma, MDSCC moderately differentiated squamous cell carcinoma, PDSCC poorly differentiated squamous cell carcinoma, T1a tumor invades mucosa, T1b tumor invades submucosa, $T 2$ tumor invades muscularis propria, $T 3$ tumor invades adventitia

*Data were analyzed by Cox regression analysis. $p<0.05$ was considered statistically significant

${ }^{a}$ According to the Japanese Classification of Esophageal Cancer [13]

${ }^{\mathrm{b}}$ According to the TNM classification by UICC [14]

${ }^{c}$ Expression of $\alpha$ SMA and FAP in ESCC tissue was divided into high and low groups

${ }^{\mathrm{d}}$ The median values of CD68-positive, CD163-positive or CD204-positive macrophage numbers in cancer nests and stroma within the areas were used to divide the patients into low and high groups 


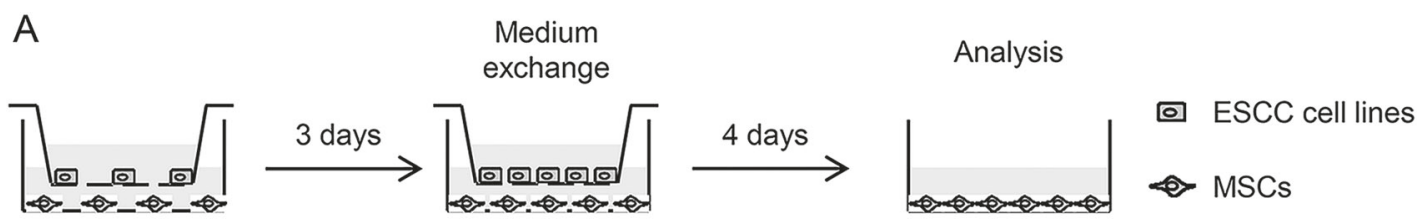

B

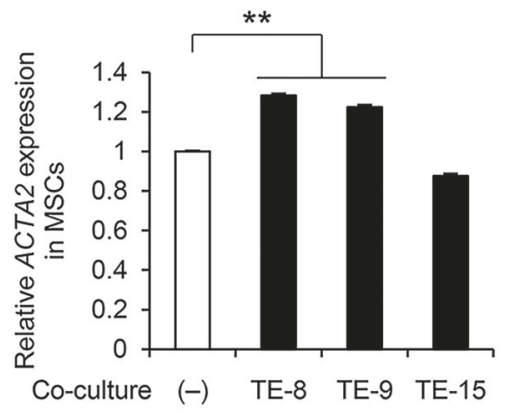

C

Co-culture (-) TE-8 TE-9 TE-15
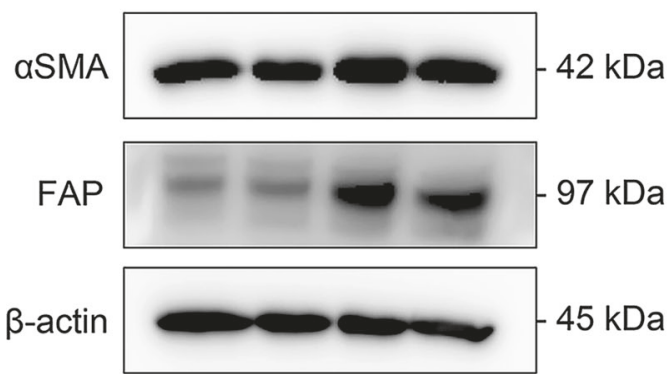

D

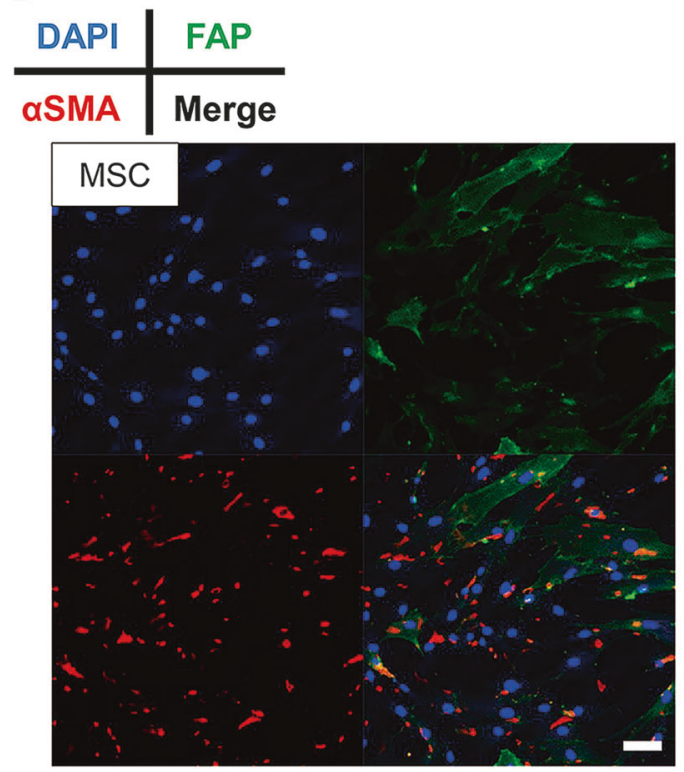

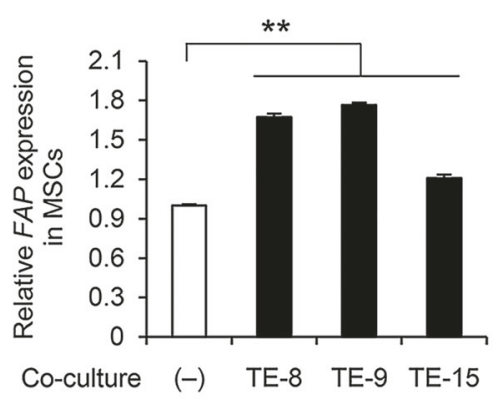

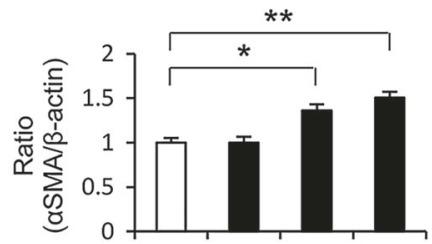

Co-culture (-) TE-8 TE-9 TE-15

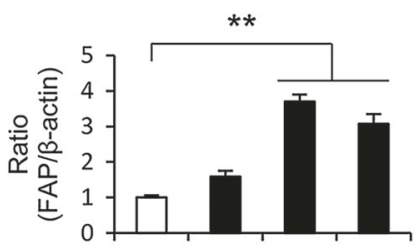

Co-culture (-) TE-8 TE-9 TE-15

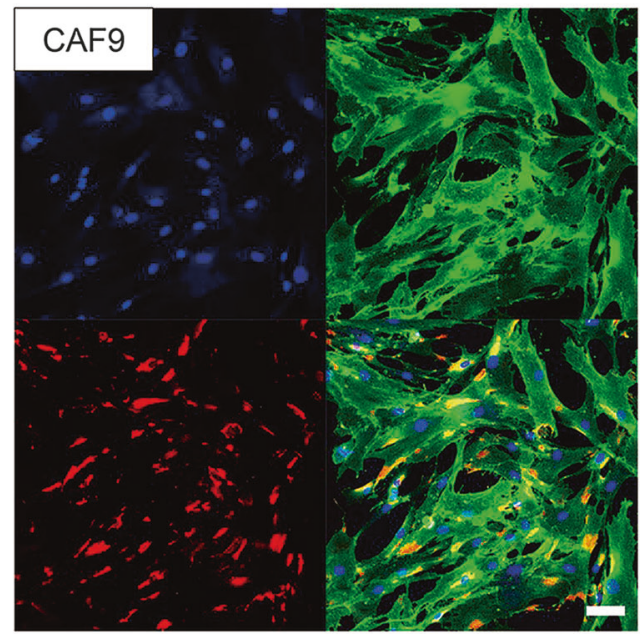


Fig. 2 CAF-like cells were induced from MSCs co-cultured with TE series esophageal squamous cell carcinoma cells. a MSCs were cocultured with TE-8, TE- 9 or TE- 15 cells for 7 days using a cell culture insert with a $0.4-\mu \mathrm{m}$ pore size filter. The medium was changed 3 days after seeding. b The mRNA expression levels of ACTA2 ( $\alpha S M A)$ and $F A P$ in MSCs and MSCs co-cultured with TE cell lines were determined by quantitative RT-PCR, normalized to ACTB ( $\beta$-actin) expression. Data are the mean \pm SEM of triplicate wells and are representative of three independent experiments $(* p<0.05, * * p<$ $0.01)$. $\mathbf{c}$ The protein levels of $\alpha$ SMA, FAP and $\beta$-actin in MSCs and MSCs co-cultured with TE cells were confirmed by western blotting. Densitometric analyses of bands were performed with ImageJ software ver. 1.51 . The results are the mean \pm SEM. $* p<0.05, * * p<0.01$. d Double immunofluorescence analyses were performed using anti$\alpha$ SMA (red) and anti-FAP (green) antibodies on MSCs or MSCs cocultured with TE-9 cells (CAF9). Nuclei were stained with DAPI (blue). Magnification: 200×. Scale bar $20 \mu \mathrm{m}$

proliferation of TE-9 cells or macrophage-like cells (data not shown), the cell migrations of TE-9 cells and macrophage-like cells were suppressed when CCL2 or IL-6 was neutralized. Anti-CXCL8 antibody had a tendency to suppress the cell migration of TE-9 cells (Fig. 4c, d).

\section{Knockdown of FAP in CAF9 cells attenuated migration of TE-9 cells and macrophage-like cells and suppressed expression of CD163, IL10, and CD274 in macrophage-like cells}

As FAP was reported to regulate cytokine secretion in fibroblasts [16], we silenced FAP in CAF9 cells using siRNA and examined the effects on TE-9 cells and macrophage-like cells (Fig. 5a). Knockdown of FAP in CAF9 cells suppressed the migration of co-cultured TE-9 cells and macrophage-like cells (Fig. 5b). Moreover, CD163, IL10, and CD274 expression in co-cultured macrophage-like cells were attenuated by the knockdown of FAP in CAF9 cells (Fig. 5c). These results suggested that FAP in CAFs plays an important role in tumor promotion and immunosuppression.

\section{Knockdown of FAP in CAF9 cells downregulated PTEN/Akt and MEK/Erk signaling pathways and suppressed the secretion of CCL2, IL-6 and CXCL8}

To identify the factors that attenuate the promoting effect on co-cultured TE-9 and macrophage-like cells through the knockdown of FAP in CAF9 cells, we analyzed cytokine secretion from FAP-silenced CAF9 cells. The cytokine array and ELISA showed that secretion of CCL2, IL-6, and CXCL8 from CAF9 cells were suppressed by the knockdown of FAP (Fig. 6a, b). Similar results were obtained using an siRNA with a second independent sequence (Supplementary Fig. S2).
Next, we examined the signaling pathways that could account for the connection between FAP expression and cytokine secretion. As Wang et al. reported that reduced FAP significantly decreased phosphorylated PI3K, Akt, MEK1/2, Erk1/2, and GSK-3 $\beta$ but upregulated PTEN in oral squamous cell carcinoma cells [17], we examined these protein levels in CAF9 cells and FAP-silenced CAF9 cells. Compared to the MSCs, the CAF9 cells showed not only the induction of FAP, phosphorylated Akt, MEK1/2, Erk1/ 2 , GSK-3 $\beta$, and total $\beta$-catenin but also the reduction of phosphorylated PTEN. The FAP-silenced CAF9 cells showed the opposite results, that is, phosphorylated Akt, MEK1/2, Erk1/2, GSK-3 $\beta$ and total $\beta$-catenin were reduced and phosphorylated PTEN was induced (Fig. 6c, Supplementary Fig. S3).

These results indicate that FAP interacts with the PTEN/ Akt and MEK/Erk signaling pathways to regulate GSK-3 $\beta$ phosphorylation and $\beta$-catenin expression. In addition, another important transcription factor in cytokine secretion, $\mathrm{NF}-\kappa \mathrm{B}$ (p65), was also upregulated according to the differentiation to CAF and inversely downregulated according to the knockdown of FAP. We then treated CAF9 cells with LY294002 $(20 \mu \mathrm{M})$, a PI3K inhibitor, and PD98059 (20 $\mu \mathrm{M})$, a MEK1/2 inhibitor. The secretion of CCL2, IL-6, and CXCL8 from CAF9 cells were suppressed by both LY294002 and PD98059 (Fig. 6d). In addition, Bay11-7082 $(2 \mu \mathrm{M})$, an NF- $\mathrm{NB}$ inhibitor, completely attenuated these cytokine secretion, and MSAB $(20 \mu \mathrm{M})$, a $\beta$ catenin inhibitor, attenuated the secretion of CCL2 and CXCL8 (Fig. 6d). Based on these findings, we speculate that FAP regulates cytokine secretion from CAF9 cells through PI3K/Akt and MEK/Erk signaling with downstream targets.

\section{Discussion}

The expression of CAF markers have recently been shown to have prognostic value in several cancers. FAP was a predictor for poor prognosis in non-small cell lung cancer [18]. Ha et al. reported that the stromal-cell expression of CAF markers, such as $\alpha$ SMA, FSP-1, and PDGFR- $\alpha$ were unfavorable prognostic factors in patients with ESCC [19]. In their article, FAP was not a significant prognostic factor for overall and disease-free survival. Our present findings showed that the $\alpha$ SMA and FAP expression in the ESCC stroma are correlated with the depth of tumor invasion, lymph node metastasis, advanced pathological stage and poor disease-free survival. In our assessment, in contrast to a recent publication [19], FAP expression but not $\alpha$ SMA expression was significantly correlated with poor overall survival. We believe that the reasons for this discrepancy 

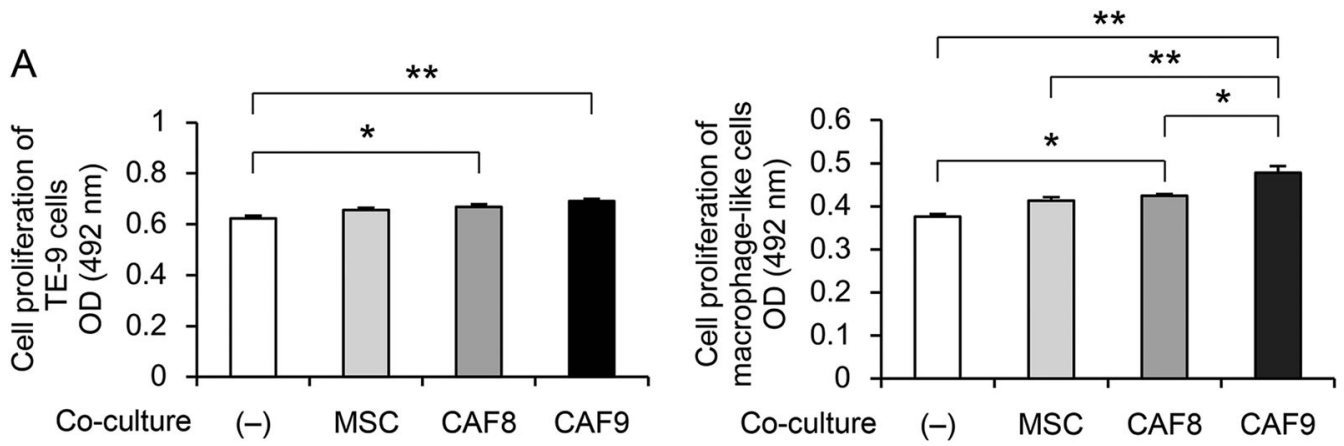

B
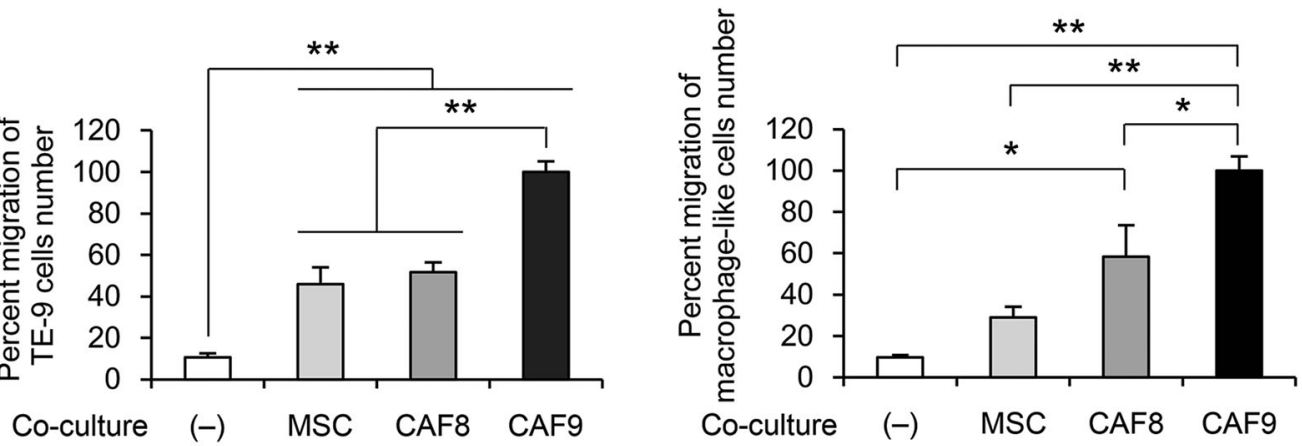

$\mathrm{C}$
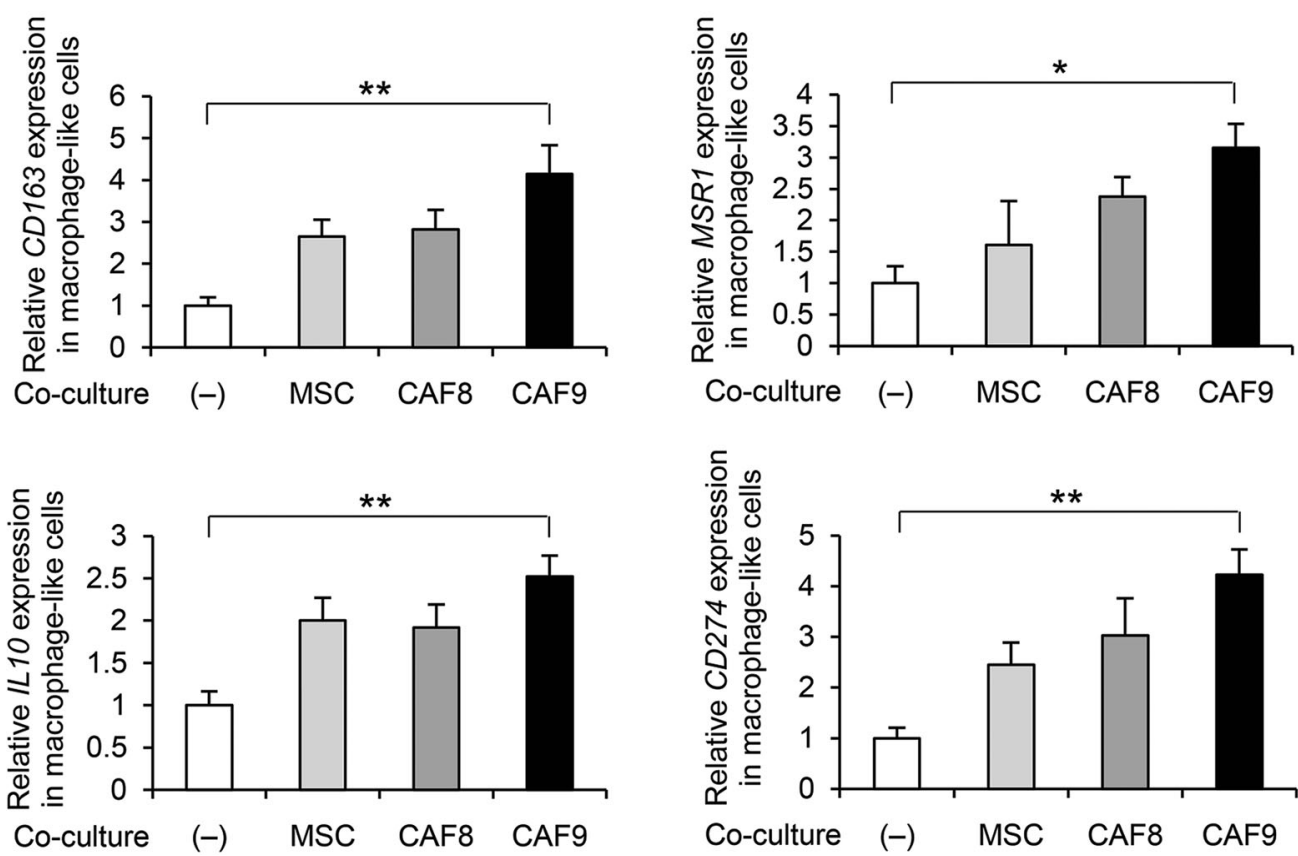

Fig. 3 CAF9 cells promoted the cell growth and migration of TE-9 cells and macrophage-like cells and induced the M2 polarization of macrophage-like cells. a The effects of co-culture with MSCs, CAF8 or CAF9 cells on the cell proliferation of TE-9 cells (left) or macrophage-like cells (right) were assessed by MTS colorimetric assay. The results are the mean \pm SEM of triplicate wells and are representative of three independent experiments $(* p<0.05$, ** $p<$ 0.01). b The effects of co-culture with MSCs, CAF8 or CAF9 cells on the migration of TE-9 cells (left) or macrophage-like cells (right) were analyzed by transwell migration assay. Migrating cells were counted in

four randomly chosen fields. The results are the mean \pm SEM of triplicate wells and are representative of three independent experiments $(* p<0.05, * * p<0.01)$. c The mRNA expression levels of CD163 (upper left), MSR1 (CD204) (upper right), IL10 (lower left) and CD274 (PD-L1) (lower right) in macrophage-like cells co-cultured with MSCs, CAF8 or CAF9 cells were determined by quantitative RTPCR, normalized to ACTB ( $\beta$-actin) expression. Data are the mean \pm SEM of triplicate wells and are representative of three independent experiments $\left(* p<0.05,{ }^{* *} p<0.01\right)$ 
A
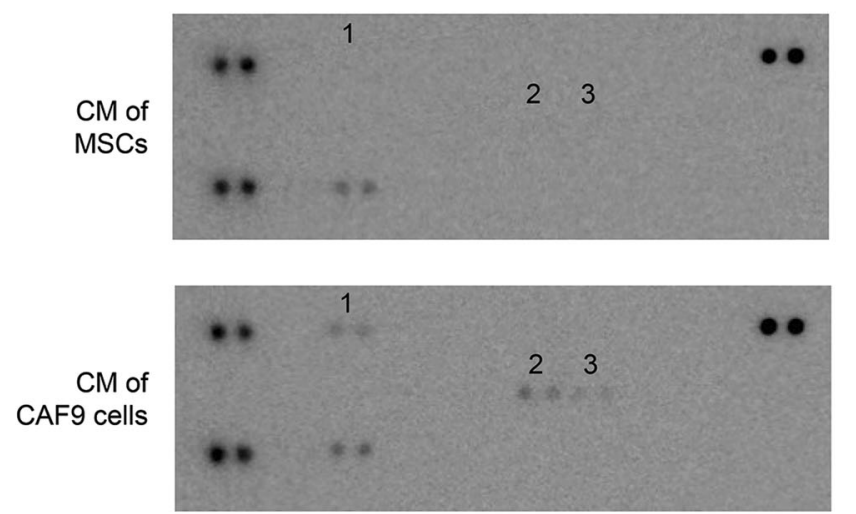

1. CCL2

2. IL6

3. CXCL8

C
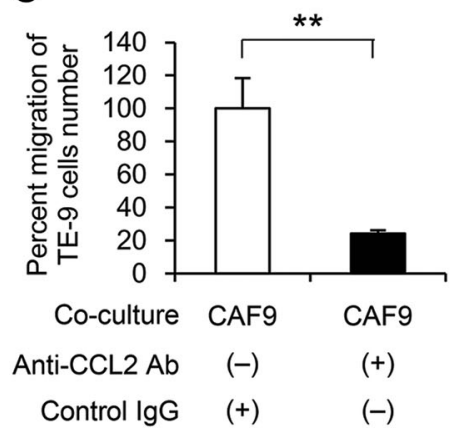

D

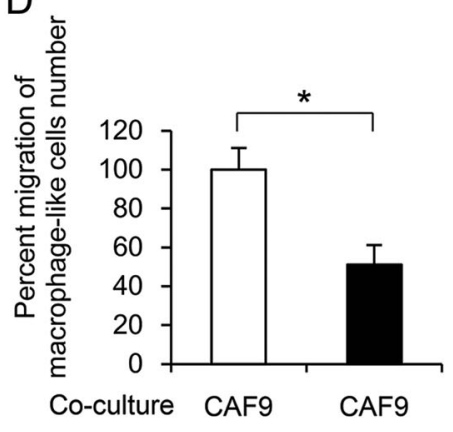

Anti-CCL2 Ab (-)

Control lgG (+)

Anti-IL6 Ab (-)

$(+)$

(-)

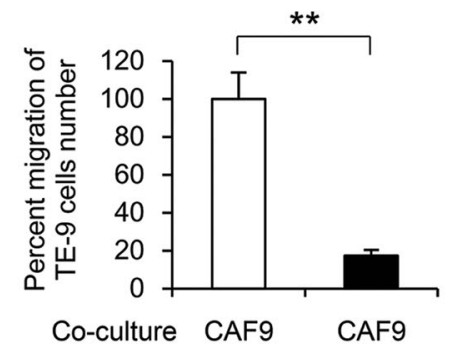

Anti-IL6 Ab (-)

Control IgG

$(+)$

(-)
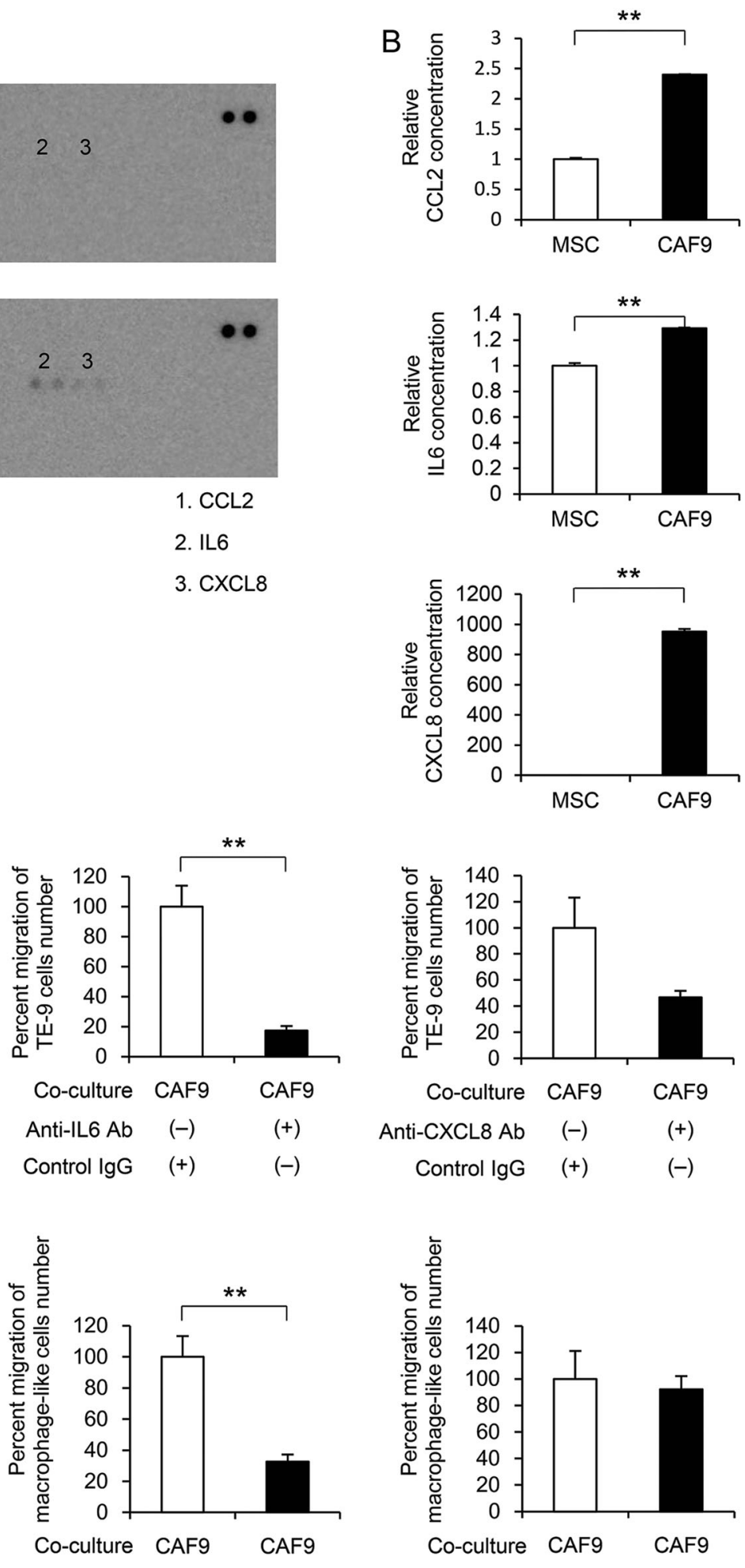

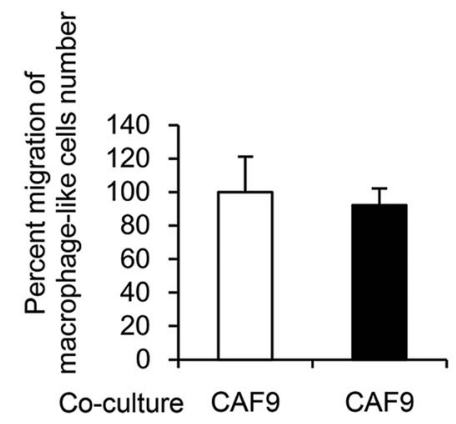

Anti-CXCL8 Ab (-)

(+)

Control IgG (+)
$(+)$

$(-)$ are as follows. First, the CAF marker measurements were different in two studies. We evaluated only the immunohistochemistry-positive area while the previous study evaluated staining area and intensity. Next, the ratio of $\mathrm{T} 1$ stage patients in our study was larger than in the previous study (70\% vs. $12.9 \%)$. This could mean 
4 Fig. 4 The secretion of CCL2, IL-6, and CXCL8 were induced in CAF9 cells, and promoted the migration of TE-9 cells and macrophage-like cells. a CAF9 cells were cultured in serum-free conditions for $24 \mathrm{~h}$, and the conditioned medium (CM) was analyzed by a Proteome Profiler Human Cytokine Array Kit. The CM of MSCs was used as the control. b Relative concentrations of CCL2, IL-6 and CXCL8 protein in the CM of MSCs and CAF9 cells. The concentrations were measured by ELISA and normalized to the total protein of cell lysate. Data are the mean \pm SEM of triplicate wells and are representative of three independent experiments $(* p<0.05, * * p<$ 0.01). c The effects of CCL2, IL-6, and CXCL8 neutralizing antibodies on the migration of TE-9 cells co-cultured with CAF9 cells were investigated using a transwell migration assay. Normal Armenian hamster IgG isotype was used as a control for CCL2. Normal mouse IgG isotype was used as a control for IL-6 and CXCL8. Data are the mean \pm SEM of triplicate wells and are representative of three independent experiments $(* * p<0.01)$. d The effect of CCL2, IL-6, and CXCL8 neutralizing antibodies on the migration of macrophage-like cells co-cultured with CAF9 cells was investigated using a transwell migration assay. Normal Armenian hamster IgG isotype was used as a control for CCL2. Normal mouse IgG isotype was used as a control for IL-6 and CXCL8. Data are the mean \pm SEM of triplicate wells and are representative of three independent experiments $(* p<0.05$, ** $p<$ $0.01)$

that FAP expression is especially important in early-stage ESCC. Expression levels of $\alpha$ SMA and FAP differed in some cases. CAFs are a heterogeneous population due to their varied origins, and they consist of activated and non-activated fibroblast populations. Kidd et al. reported that FAP- and FSP-1-positive CAFs originate largely from MSCs in bone marrow, whereas $\alpha$ SMA-positive CAFs are derived mainly from local tissues, such as adipose tissue [20].

Since we consider FAP to be a variable prognostic factor in ESCC, we next investigated whether ESCC cells could induce FAP expression in MSCs in vitro. Our previous study demonstrated significant $\alpha$ SMA and FAP induction in MSCs when they were exposed to conditioned media of neuroblastoma cell lines [12]. In this study, we observed significant FAP induction in MSCs co-cultured with ESCC cells. In our co-culture experiment, these FAP-positive CAF-like cells showed the tumor-promoting phenotype through the increased secretion of cytokines, such as CCL2, IL-6, and CXCL8. CCL2 enhances tumor cell growth and migration [21]. IL-6 not only promotes the growth of tumor cells but also induces the epithelial-mesenchymal transition of tumor cells to enhance tumor cell migration and chemoresistance [22, 23]. CXCL8 is associated with tumor progression through the promotion of cell migration and invasion [24]. In addition to the promoting effects on tumor cells themselves, these cytokines contribute to the immunosuppressive properties of the tumor microenvironment.

CCL2 is known to induce the M2 polarization of macrophages and to recruit regulatory $\mathrm{T}$ cells and myeloidderived suppressor cells (MDSCs) [25, 26]. IL-6 mediates immunosuppression through the generation of TAMs and the inhibition of $\mathrm{NF}-\kappa \mathrm{B}$ binding activity in dendritic cells [27, 28] and also upregulates PD-L1 expression in nonsmall cell lung cancer and ESCC $[29,30]$. CXCL8 recruits neutrophils and MDSCs [31, 32]. These findings indicate that the effects of CAF-like cells on tumor progression are based on various factors that affect tumor cells directly and indirectly. We thus focused on the effect of CAF-like cells on macrophage-like cells, and our findings confirmed the promotion of macrophage-like cell proliferation and migration and the induction of M2 polarization.

M2 macrophages compose a major part of the TAMs and promote tumor progression [10]. Some scavenger receptors (e.g., CD163 and CD204) are known as M2 macrophage markers, and the expression of these receptors correlate with the progression of various tumors, including breast cancer, renal cancer, neuroblastoma and ESCC [33-37]. Our previous study showed that M2 macrophages directly promote tumor progression through the expression of GDF15, NCAM and CXCL8 [24, 38, 39]. M2 macrophages are also thought to provide an immunosuppressive microenvironment that is favorable for tumor growth through the secretion of anti-inflammatory molecules such as TGF- $\beta$, IL10, and arginase1 [40], and the expression of both PD-L1, and PD-L2 [41, 42]. Thus CAFs and TAMs are both tumor promotive and immunosuppressive.

Whereas CAFs and TAMs promote tumor progression independently, interactions between CAFs and TAMs have been reported in several cancers, including colorectal cancer, prostate cancer, oral squamous cell carcinoma, neuroblastoma, and pancreatic ductal adenocarcinoma [12, 43-46]. CAFs have been reported to recruit blood monocytes into tumor tissue and to promote M2 polarization [45, 46]. In our present study, the expression of $\alpha$ SMA or FAP in the ESCC stroma was correlated with a number of invading M2 macrophages, and the immunofluorescence analysis also showed that CAFs coexisted with a large number of M2 macrophages. Moreover, CAF-like cells promoted the proliferation and migration of macrophagelike cells and induced M2 polarization in vitro. These findings indicate that CAFs recruit monocytes and "educate" them to obtain an immunosuppressive phenotype. Taken together, our findings indicate that CAFs and TAMs function synergistically for tumor progression, and CAFs play a critical role in this synergy through the recruitment and M2 polarization of macrophages.

Another important finding of our study is that the cancerpromoting phenotype of CAFs is triggered by FAP expression. FAP has been reported not only to be a CAF marker but also to drive fibroblasts and tumor cells to promote tumor progression. Yang et al. reported that FAP in CAFs induced CCL2 secretion via STAT3-CCL2 signaling and promoted immunosuppression [16]. Another study demonstrated that FAP-overexpressing fibroblasts produced 
Fig. 5 Knockdown of FAP in CAF9 cells suppressed the promoting effects on the migration of TE-9 cells and macrophage-like cells and the M2 polarization of macrophagelike cells. CAF9 cells were transfected with $20 \mathrm{nM}$ siRNA targeting FAP (sc-62292, Santa Cruz). Negative control siRNA was transfected to CAF9 cells as the negative control. a Effective knockdown of FAP was confirmed by quantitative RTPCR (left) and western blotting (right). Data are the mean \pm SEM of triplicate wells and are representative of three independent experiments $(* * p<$ $0.01)$. b The effects of FAP knockdown in CAF9 cells on the migration of co-cultured TE-9 cells (left) or macrophage-like cells (right) were analyzed by transwell migration assay. Migrating cells were counted in four randomly chosen fields.

The results are the mean \pm SEM of triplicate wells and are representative of three independent experiments $(* p<$ 0.05). $\mathbf{c}$ The effects of FAP knockdown in CAF9 cells on the M2 polarization of macrophagelike cells were analyzed. The mRNA expression levels of CD163 (upper left), MSR1 (CD204) (upper right), IL10 (lower left) and CD274 (PD-L1) (lower right) in macrophage-like cells co-cultured with FAPsilenced CAF9 cells were determined by quantitative RTPCR, normalized to ACTB ( $\beta$ actin) expression. Data are the mean \pm SEM of triplicate wells and are representative of three independent experiments $(* p<$ $0.05, * * p<0.01$ )
A
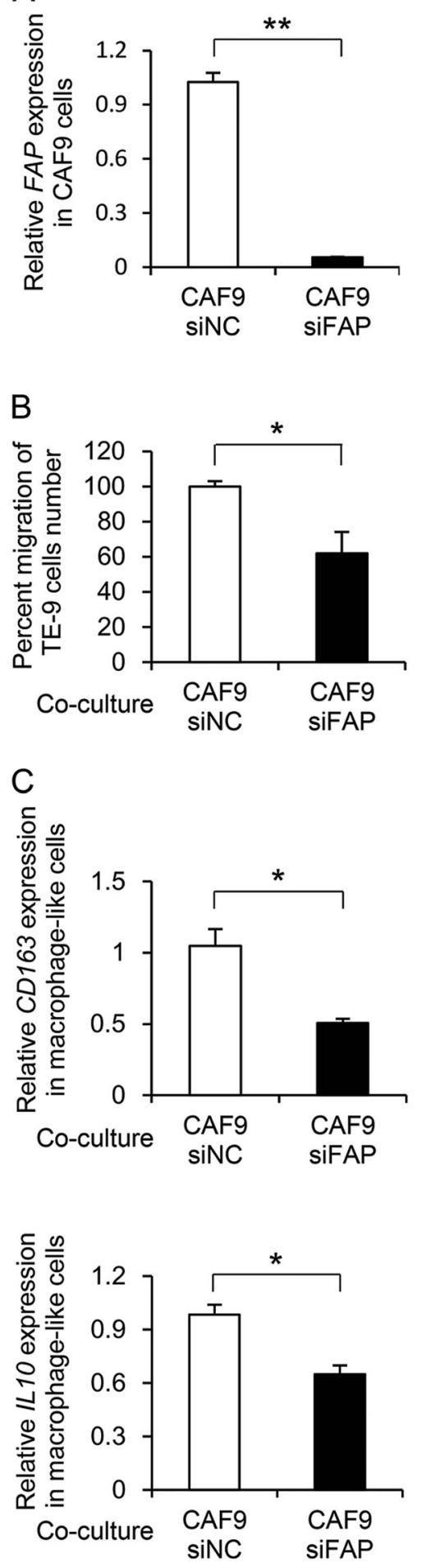
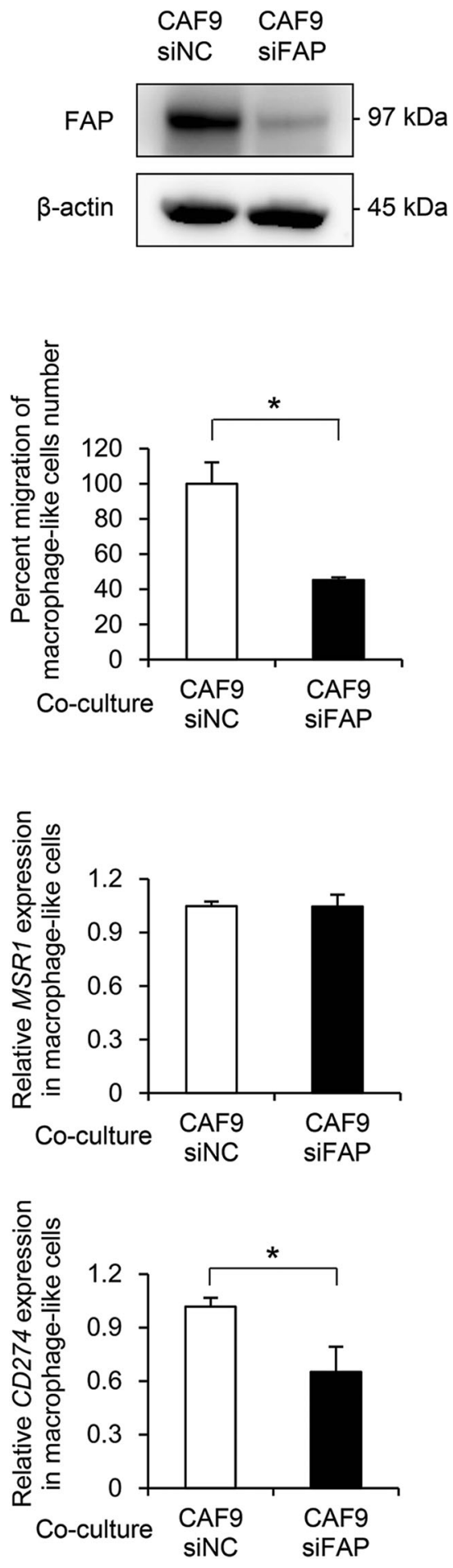

an extracellular matrix that enhanced the invasiveness of pancreatic cancer cells [47].

In several types of tumor cells, FAP expression was associated with cell growth and metastasis [17, 48]. Specifically, Wang et al. reported that the downregulation of FAP in oral squamous cell carcinoma inactivated PTEN/
PI3K/Akt and Ras-Erk signaling to suppress the proliferation and metastasis of tumor cells. These studies indicate that FAP exerts specific effects to regulate cell signaling and change cell behavior, including cytokine secretion. In the present study, FAP activated PTEN/Akt and MEK/Erk signaling, resulting in the increase of $\beta$-catenin and NF- $\kappa \mathrm{B}$ 
A
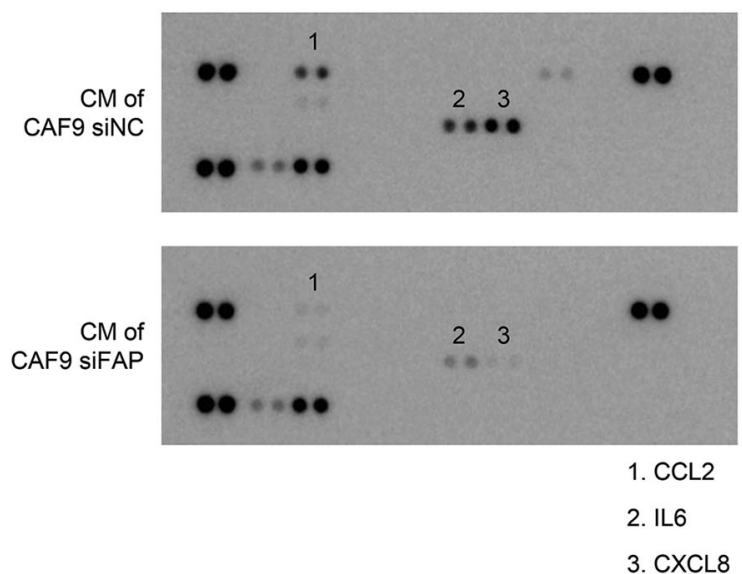

C

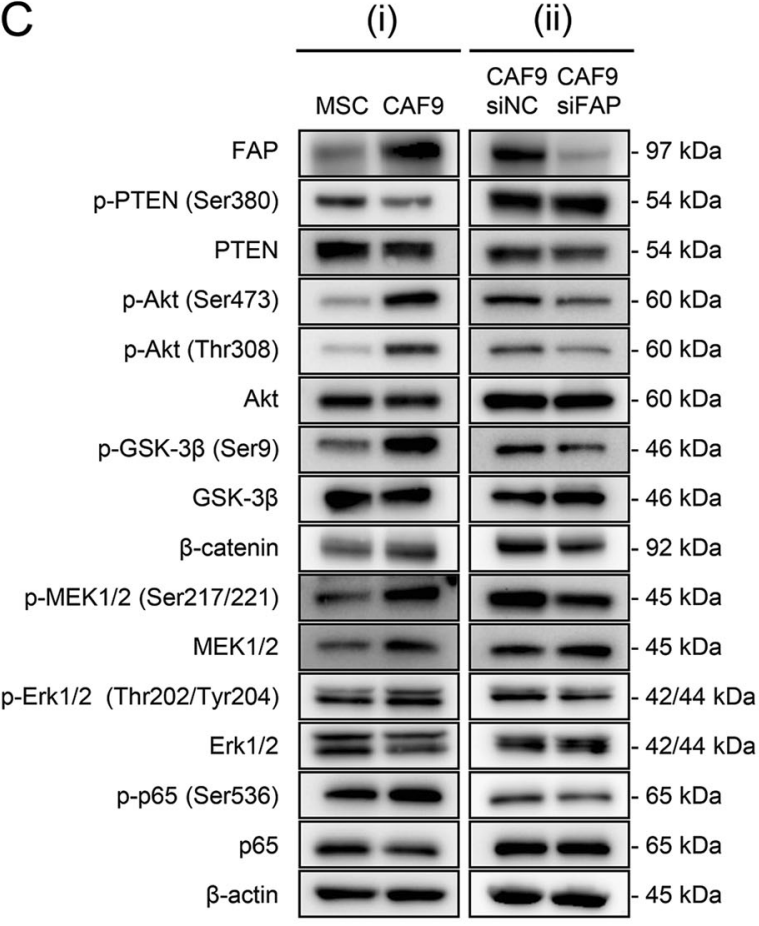

B
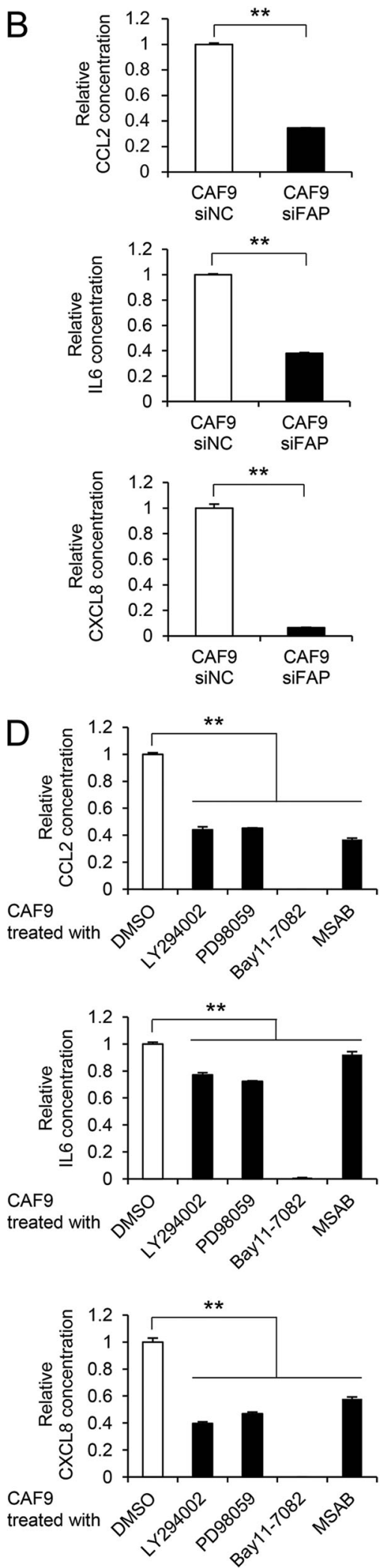

activity in CAF-like cells, and FAP promoted the secretion of CCL2, IL-6 and CXCL8. Although the precise details of the initiation of signal activation by FAP have not yet been elucidated, the phosphorylation of Akt and Erk signaling leads to the activation of some transcription factors. For instance, Akt and Erk signaling are responsible for the 
Fig. 6 Knockdown of FAP in CAF9 cells suppressed the PTEN/Akt and MEK/Erk signaling pathways and attenuated the secretion of CCL2, IL-6 and CXCL8. a FAP-silenced CAF9 cells were cultured in serum-free conditions for $24 \mathrm{~h}$, and the CM was analyzed with a Proteome Profiler Human Cytokine Array Kit. b Relative concentrations of CCL2, IL- 6 and CXCL8 protein in the CM of FAP-silenced CAF9 cells. The concentrations were measured by ELISA and normalized to the total protein of cell lysate. Data are the mean \pm SEM of triplicate wells and are representative of three independent experiments $(* * p<0.01)$. c Western blotting was conducted with total protein extracted from MSCs or CAF9 cells (i) and FAP-silenced CAF9 cells (ii) using specific antibodies as described in the Materials and Methods section. d CAF9 cells were treated with an inhibitor against PI3K

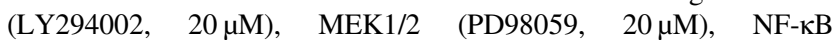
(Bay11-7082, $2 \mu \mathrm{M})$ or $\beta$-catenin (MSAB, 20 $\mu \mathrm{M}$ ) and the concentrations of CCL2, IL-6 and CXCL8 protein in their CM were measured by ELISA. DMSO was added to the negative control. The concentrations were normalized to the total protein of cell lysate. Data are the mean \pm SEM of triplicate wells and are representative of three independent experiments $(* * p<0.01)$

phosphorylation of GSK-3 $\beta[49,50]$. As active GSK-3 $\beta$ degrades $\beta$-catenin through ubiquitination, an increase of phosphorylated GSK-3 $\beta$ brings about $\beta$-catenin accumulation [51]. NF- $\mathrm{KB}$, another important transcriptional factor that is involved in cytokine secretion, is also activated by Akt and Erk signaling [52, 53]. In our study, $\beta$-catenin and $\mathrm{NF}-\kappa \mathrm{B}$ were responsible for cytokine secretion from CAFlike cells; this is consistent with several previous reports $[54,55]$.

In conclusion, the results of our present study clarify the mechanisms of tumor-promotive and immunosuppressive phenotypes of FAP-positive cancer-associated fibroblasts in ESCC. Although the mechanism of signal activation by FAP must be elucidated, FAP in cancer-associated fibroblasts has a variable prognostic value in ESCC patients and, together with its downstream factors, FAP could become a specific target of anti-cancer therapy.

Acknowledgements This work was supported by JSPS KAKENHI Grant Numbers JP17K08693, JP17K17247 and JP16K21159. We thank Atsuko Kawashima, Yumi Hashimoto, Nobuo Kubo and Miki Yamazaki for their excellent technical assistance.

\section{Compliance with ethical standards}

Conflict of interest The authors declare that they have no conflict of interest.

Publisher's note: Springer Nature remains neutral with regard to jurisdictional claims in published maps and institutional affiliations.

\section{References}

1. Pennathur A, Gibson MK, Jobe BA, Luketich JD. Oesophageal carcinoma. Lancet. 2013;381:400-12.

2. Rustgi AK, El-Serag HB. Esophageal carcinoma. N Engl J Med. 2014;371:2499-509.
3. Tachimori Y, Ozawa S, Numasaki H, Ishihara R, Matsubara H, Muro K, et al. Comprehensive registry of esophageal cancer in Japan, 2009. Esophagus. 2016;13:110-37.

4. Malhotra GK, Yanala U, Ravipati A, Follet M, Vijayakumar M, Are C. Global trends in esophageal cancer. J Surg Oncol. 2017;115:564-79.

5. Nakagawa S, Kanda T, Kosugi S, Ohashi M, Suzuki T, Hatakeyama K. Recurrence pattern of squamous cell carcinoma of the thoracic esophagus after extended radical esophagectomy with three-field lymphadenectomy. J Am Coll Surg. 2004;198:205-11.

6. Li H, Fan X, Houghton J. Tumor microenvironment: the role of the tumor stroma in cancer. J Cell Biochem. 2007;101:805-15.

7. Lin EW, Karakasheva TA, Hicks PD, Bass AJ, Rustgi AK. The tumor microenvironment in esophageal cancer. Oncogene. 2016;35:5337-49.

8. De Wever O, Demetter P, Mareel M, Bracke M. Stromal myofibroblasts are drivers of invasive cancer growth. Int $\mathrm{J}$ Cancer. 2008;123:2229-38.

9. Shiga K, Hara M, Nagasaki T, Sato T, Takahashi H, Takeyama H. Cancer-associated fibroblasts: their characteristics and their roles in tumor growth. Cancers (Basel). 2015;7:2443-58.

10. Takeya M, Komohara Y. Role of tumor-associated macrophages in human malignancies: friend or foe? Pathol Int. 2016;66:491-505.

11. Komohara Y, Takeya M. CAFs and TAMs: maestros of the tumour microenvironment. J Pathol. 2017;241:313-5.

12. Hashimoto O, Yoshida M, Koma Y, Yanai T, Hasegawa D, Kosaka Y, et al. Collaboration of cancer-associated fibroblasts and tumour-associated macrophages for neuroblastoma development. J Pathol. 2016;240:211-23.

13. Japan Esopageal Society. Japanese Classification of Esophageal Cancer. 10th ed. Tokyo: Kanehara \& Co; 2008.

14. TNM Classification of Malignant Tumours. 7th ed. Hoboken: Wiley-Blackwell; 2011.

15. Nishihira T, Hashimoto $\mathrm{Y}$, Katayama M, Mori S, Kuroki T. Molecular and cellular features of esophageal cancer cells. J Cancer Res Clin Oncol. 1993;119:441-9.

16. Yang X, Lin Y, Shi Y, Li B, Liu W, Yin W, et al. FAP promotes immunosuppression by cancer-associated fibroblasts in the tumor microenvironment via STAT3-CCL2 signaling. Cancer Res. 2016;76:4124-35.

17. Wang H, Wu Q, Liu Z, Luo X, Fan Y, Liu Y, et al. Downregulation of FAP suppresses cell proliferation and metastasis through PTEN/PI3K/AKT and Ras-ERK signaling in oral squamous cell carcinoma. Cell Death Dis. 2014;5:e1155.

18. Liao Y, Ni Y, He R, Liu W, Du J. Clinical implications of fibroblast activation protein-alpha in non-small cell lung cancer after curative resection: a new predictor for prognosis. J Cancer Res Clin Oncol. 2013;139:1523-8.

19. Ha SY, Yeo SY, Xuan YH, Kim SH. The prognostic significance of cancer-associated fibroblasts in esophageal squamous cell carcinoma. PLoS One. 2014;9:e99955.

20. Kidd S, Spaeth E, Watson K, Burks J, Lu H, Klopp A, et al. Origins of the tumor microenvironment: quantitative assessment of adipose-derived and bone marrow-derived stroma. PLoS One. 2012;7:e30563.

21. Li X, Xu Q, Wu Y, Li J, Tang D, Han L, et al. A CCL2/ROS autoregulation loop is critical for cancer-associated fibroblastsenhanced tumor growth of oral squamous cell carcinoma. Carcinogenesis. 2014;35:1362-70.

22. Zhu L, Cheng X, Ding Y, Shi J, Jin H, Wang H, et al. Bone marrow-derived myofibroblasts promote colon tumorigenesis through the IL-6/JAK2/STAT3 pathway. Cancer Lett. 2014;343:80-89.

23. Shintani Y, Fujiwara A, Kimura T, Kawamura T, Funaki S, Minami M, et al. IL-6 secreted from cancer-associated fibroblasts 
mediates chemoresistance in NSCLC by increasing epithelialmesenchymal transition signaling. J Thorac Oncol. 2016;11:1482-92.

24. Hosono M, Koma YI, Takase N, Urakawa N, Higashino N, Suemune K, et al. CXCL8 derived from tumor-associated macrophages and esophageal squamous cell carcinomas contributes to tumor progression by promoting migration and invasion of cancer cells. Oncotarget. 2017;8:106071-88.

25. Roca H, Varsos ZS, Sud S, Craig MJ, Ying C, Pienta KJ. CCL2 and interleukin-6 promote survival of human CD11b+peripheral blood mononuclear cells and induce M2-type macrophage polarization. J Biol Chem. 2009;284:34342-54.

26. Chang AL, Miska J, Wainwright DA, Dey M, Rivetta CV, Yu D, et al. CCL2 produced by the glioma microenvironment is essential for the recruitment of regulatory $\mathrm{T}$ cells and myeloid-derived suppressor cells. Cancer Res. 2016;76:5671-82.

27. Hegde S, Pahne J, Smola-Hess S. Novel immunosuppressive properties of interleukin-6 in dendritic cells: inhibition of NFkappaB binding activity and CCR7 expression. FASEB J. 2004;18:1439-41.

28. Jeannin P, Duluc D, Delneste Y. IL-6 and leukemia-inhibitory factor are involved in the generation of tumor-associated macrophage: regulation by IFN-gamma. Immunotherapy. 2011;3:23-26.

29. Zhang N, Zeng Y, Du W, Zhu J, Shen D, Liu Z, et al. The EGFR pathway is involved in the regulation of PD-L1 expression via the IL-6/JAK/STAT3 signaling pathway in EGFR-mutated non-small cell lung cancer. Int J Oncol. 2016;49:1360-8.

30. Chen MF, Chen PT, Chen WC, Lu MS, Lin PY, Lee KD. The role of PD-L1 in the radiation response and prognosis for esophageal squamous cell carcinoma related to IL-6 and T-cell immunosuppression. Oncotarget. 2016;7:7913-24.

31. Haqqani AS, Sandhu JK, Birnboim HC. Expression of interleukin-8 promotes neutrophil infiltration and genetic instability in mutatect tumors. Neoplasia. 2000;2:561-8.

32. Alfaro C, Teijeira A, Onate C, Perez G, Sanmamed MF, Andueza MP, et al. Tumor-produced interleukin- 8 attracts human myeloidderived suppressor cells and elicits extrusion of neutrophil extracellular traps (NETs). Clin Cancer Res. 2016;22:3924-36.

33. Shabo I, Stal O, Olsson H, Dore S, Svanvik J. Breast cancer expression of CD163, a macrophage scavenger receptor, is related to early distant recurrence and reduced patient survival. Int $\mathbf{J}$ Cancer. 2008;123:780-6.

34. Miyasato Y, Shiota T, Ohnishi K, Pan C, Yano H, Horlad H, et al. High density of CD204-positive macrophages predicts worse clinical prognosis in patients with breast cancer. Cancer Sci. 2017;108:1693-1700.

35. Komohara Y, Hasita H, Ohnishi K, Fujiwara Y, Suzu S, Eto M, et al. Macrophage infiltration and its prognostic relevance in clear cell renal cell carcinoma. Cancer Sci. 2011;102:1424-31.

36. Asgharzadeh S, Salo JA, Ji L, Oberthuer A, Fischer M, Berthold $\mathrm{F}$, et al. Clinical significance of tumor-associated inflammatory cells in metastatic neuroblastoma. J Clin Oncol. 2012;30:3525-32.

37. Shigeoka M, Urakawa N, Nakamura T, Nishio M, Watajima T, Kuroda D, et al. Tumor associated macrophage expressing CD204 is associated with tumor aggressiveness of esophageal squamous cell carcinoma. Cancer Sci. 2013;104:1112-9.

38. Urakawa N, Utsunomiya S, Nishio M, Shigeoka M, Takase N, Arai N, et al. GDF15 derived from both tumor-associated macrophages and esophageal squamous cell carcinomas contributes to tumor progression via Akt and Erk pathways. Lab Invest. 2015;95:491-503.
39. Takase N, Koma Y, Urakawa N, Nishio M, Arai N, Akiyama H, et al. NCAM- and FGF-2-mediated FGFR1 signaling in the tumor microenvironment of esophageal cancer regulates the survival and migration of tumor-associated macrophages and cancer cells. Cancer Lett. 2016;380:47-58.

40. Hao NB, Lu MH, Fan YH, Cao YL, Zhang ZR, Yang SM. Macrophages in tumor microenvironments and the progression of tumors. Clin Dev Immunol. 2012;2012:948098.

41. Huber S, Hoffmann R, Muskens F, et al. Alternatively activated macrophages inhibit T-cell proliferation by Stat6-dependent expression of PD-L2. Blood. 2010;116:3311-20.

42. Gottlieb CE, Mills AM, Cross JV, Ring KL. Tumor-associated macrophage expression of PD-L1 in implants of high grade serous ovarian carcinoma: A comparison of matched primary and metastatic tumors. Gynecol Oncol. 2017;144:607-12.

43. Herrera M, Herrera A, Dominguez G, Silva J, Garcia V, Garcia $\mathrm{JM}$, et al. Cancer-associated fibroblast and M2 macrophage markers together predict outcome in colorectal cancer patients. Cancer Sci. 2013;104:437-44.

44. Comito G, Giannoni E, Segura CP, Barcellos-de-Souza P, Raspollini MR, Baroni G, et al. Cancer-associated fibroblasts and M2polarized macrophages synergize during prostate carcinoma progression. Oncogene. 2014;33:2423-31.

45. Takahashi H, Sakakura K, Kudo T, Toyoda M, Kaira K, Oyama $\mathrm{T}$, et al. Cancer-associated fibroblasts promote an immunosuppressive microenvironment through the induction and accumulation of protumoral macrophages. Oncotarget. 2017;8:8633-47.

46. Zhang A, Qian Y, Ye Z, Chen H, Xie H, Zhou L, et al. Cancerassociated fibroblasts promote M2 polarization of macrophages in pancreatic ductal adenocarcinoma. Cancer Med. 2017;6:463-70.

47. Lee HO, Mullins SR, Franco-Barraza J, Valianou M, Cukierman E, Cheng JD. FAP-overexpressing fibroblasts produce an extracellular matrix that enhances invasive velocity and directionality of pancreatic cancer cells. BMC Cancer. 2011;11:245.

48. Huang Y, Simms AE, Mazur A, Wang S, Leon NR, Jones B, et al. Fibroblast activation protein-alpha promotes tumor growth and invasion of breast cancer cells through non-enzymatic functions. Clin Exp Metastas-. 2011;28:567-79.

49. Armstrong L, Hughes O, Yung S, Hyslop L, Stewart R, Wappler I, et al. The role of PI3K/AKT, MAPK/ERK and NFkappabeta signalling in the maintenance of human embryonic stem cell pluripotency and viability highlighted by transcriptional profiling and functional analysis. Hum Mol Genet. 2006;15:1894-913.

50. Ding Q, Xia W, Liu JC, Yang JY, Lee DF, Xia J, et al. Erk associates with and primes GSK-3beta for its inactivation resulting in upregulation of beta-catenin. Mol Cell. 2005;19:159-70.

51. Willert K, Nusse R. Beta-catenin: a key mediator of Wnt signaling. Curr Opin Genet Dev. 1998;8:95-102.

52. Jiang $\mathrm{B}, \mathrm{Xu} \mathrm{S}$, Hou $\mathrm{X}$, Pimentel DR, Brecher $\mathrm{P}$, Cohen RA. Temporal control of NF-kappaB activation by ERK differentially regulates interleukin-1beta-induced gene expression. J Biol Chem. 2004;279:1323-9.

53. Pommier Y, Sordet O, Antony S, Hayward RL, Kohn KW. Apoptosis defects and chemotherapy resistance: molecular interaction maps and networks. Oncogene. 2004;23:2934-49.

54. Manicassamy S, Reizis B, Ravindran R, Nakaya H, SalazarGonzalez RM, Wang YC, et al. Activation of beta-catenin in dendritic cells regulates immunity versus tolerance in the intestine. Science. 2010;329:849-53.

55. Hoesel B, Schmid JA. The complexity of NF-kappaB signaling in inflammation and cancer. Mol Cancer. 2013;12:86. 